\title{
THE INTEGRATION OF GIS AND SPACE SYNTAX FOR URBAN MORPHOLOGY ANALYSIS
}

\section{Tarek Z. A. Abou El Seoud}

Environmental Planning Department Faculty of Urban and Regional Planning, Cairo University

\begin{abstract}
Several urban planner researchers emphasized a need to establish a scientific basis for urban design analysis methods based on quantitative model. Researchers also argue that such methods must also take into consideration the social and spatial aspects that affects the perception of the urban morphology. The paper presents the main principles and the analysis tools of space syntax and its methodological perspectives within the GIS environment, which the outcomes should be of interest for many urban planners. The paper argues that applying such model of space syntax theory within the GIS spatial analysis environment leads for a better understanding and modeling of real-world phenomena. The paper experiments the proposed methodology and its practical evaluations of using the potential of the space syntax approach within GIS on Darb Al- Ahmar Kessm in historic Cairo.
\end{abstract}

Keywords: GIS, space syntax, urban planning and design

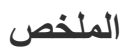

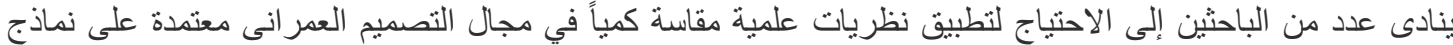

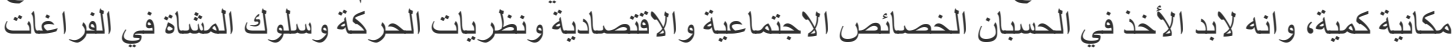

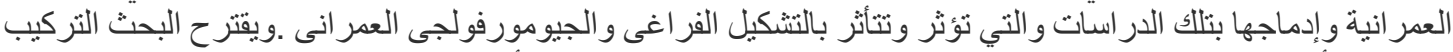

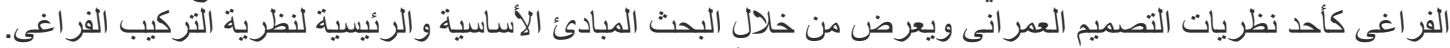

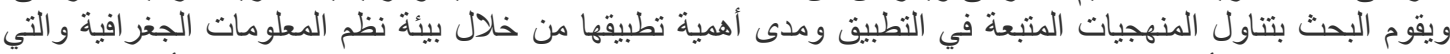

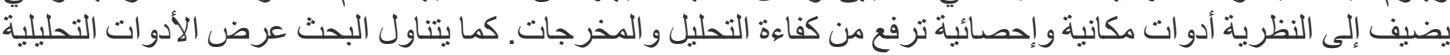

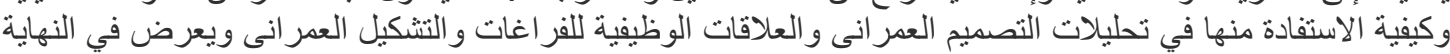

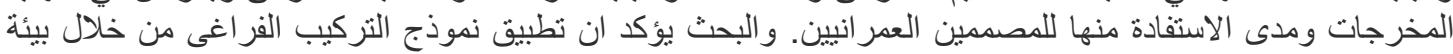

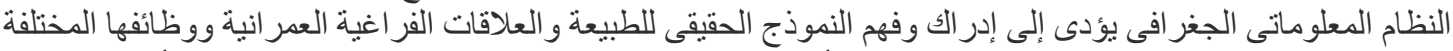

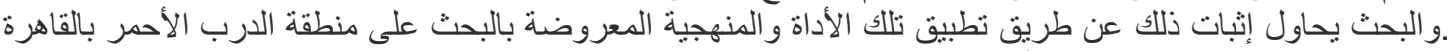

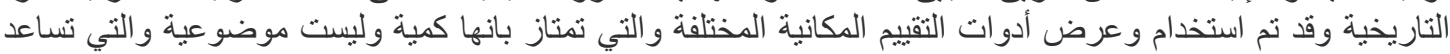
متخذى القرار من المصممين العمر انيين في اتخاذ القرار ات الصحان الصحيحة.

\section{INTRODUCTION}

Spatial analysis is one of the characteristics, which differentiate GIS from other spatial information processing. In the last decade, much effort has been made in developing Spatial Data Analysis (SDA) theories and methods for a better understanding and modeling of real-world phenomena [9]. Recent research and applications in SDA have developed many sophisticated analytical techniques for studying spatial patterns and processes. However, it is largely recognized that GIS still needs an integration of new analysis and modeling methods to achieve its potential as a general-purpose tool for environmental and urban planning [16]. The current demand for analytical tools in GIS covers a wide range of applications from the study of environmental phenomena to 
the analysis of urban and regional systems [14]. Over the past two decades, Space Syntax theory has provided important computational support for the development of spatial morphological studies, in particular for the analysis of urban systems. It has been widely used for pedestrian modeling [9], criminal analysis [13] and traffic pollution control [7]. Space Syntax provides a configurationally description of an urban structure, and attempts to explain human behaviors and social activities from a spatial configuration point of view. Most of the space syntax studies concern urban pattern issues, but the method is also relevant for studies on the scale of urban design and architecture.

The researcher believes that space syntax could provide an alternative vision and model of space for the representation of urban systems within GIS environment. As such, an integration of space syntax into GIS would stimulate researches oriented toward the analysis of urban systems at different levels of abstraction. GIS provides a rich set of spatial data integration, analysis and visualization capabilities that support urban studies on the one hand. Furthermore, the principles that underline space syntax theory can extend the modeling capabilities of GIS on the other hand, particularly in terms of the diffusion of recent advances and experimentation in the analysis of urban systems. Such integration can be of value for GIS users involved in the management and planning of urban systems.

\section{RESEARCH OBJECTIVE}

The objective of this paper is to introduce the computational and cognitive perspectives of space syntax principles to support an alternative model of space within GIS environment. The paper develops a comparative analysis of space syntax modeling concepts with conventional GIS modeling capabilities, given relevant case studies on historic Cairo region. In general, the paper identifies relevant application areas of space syntax in urban planning science. The remainder of this paper is organizing as follows. Sections 3 and 4 introduce the main principles of the space syntax approach and the space syntax GIS modeling and objects. Sections 5 and 6 present the spatial analysis tools of urban morphology using the Space Syntax GIS. All these sections will be applied on Darb Al Ahmar Kessm on historic Cairo region as a case study. Finally, section 7 draws the conclusions.

\section{SPACE SYNTAX CONCEPT}

In the past, many methods of spatial analysis have developed for a better understanding and modeling of real-world phenomena. However, there is still a need for exploration of new analytical techniques for modeling urban spaces. Space syntax models the spatial configurations of urban spaces by using a connectivity graph representation. Such a configuration of space identifies patterns that are used to study urban structures and human behaviors. 
Space Syntax is based upon the theory that the form-function relation in buildings and cities passes through the structural properties of its configuration [10]. Space syntax is a science-based, human-focused approach that investigates relationships between spatial layout and a range of social, economic and environmental phenomena. These phenomena include patterns of movement, awareness and interaction; density, land use and land value; urban growth and societal differentiation; safety and crime distribution [13]

The space syntax approach considered as a simulation tool for planners, architects of the likely effects of their designs, urban plans on the people who occupied and moved around in the buildings or urban settlements. It has since grown around the world in a variety of research areas and practical applications including archaeology, criminology, information technology, urban and human geography, anthropology and cognitive science. In practice, space syntax provides a set of planning and design principles as well as a toolkit for the generation and evaluation of ideas.

Space syntax is a kind of spatial language that is able to explain the relationship between a spatial form and the human behavior developed by Bill Hillier and his colleagues at the Bartlett School at University College London in the 1980s [10]. Space syntax theory and its analytical methods have been applied for morphological analysis in architectural design and urban form. Previous research indicates that space has its own social logic that affects human behavior such as pedestrian movement from one place to another $[8,9,10]$.

Over the past two decades, space syntax theory has provided important computational support for the development of spatial morphological studies, in particular for the analysis of urban systems. Space syntax provides a configurationally description of an urban structure, and attempts to explain human behaviors and social activities from a spatial configuration point of view.

\subsection{Space Syntax and GIS}

Space Syntax is based on a complex technique of describing the configuration that is based on topological relationships rather than on metric distances. In many cases, it has been used to inquire into social formations $[16,10]$. Space syntax could provide an alternative vision and model of space for the representation of urban systems within GIS. As such, an integration of space syntax into GIS would stimulate researches oriented toward the analysis of urban systems at different levels of abstraction. GIS provides a rich set of spatial data integration, analysis and visualization capabilities that support urban studies on the one hand. Furthermore, the principles that underline space syntax theory can extend the modeling capabilities of GIS on the other hand, particularly in terms of the diffusion of recent advances and experimentation in the analysis of urban systems. Such integration can be of value for space syntax users involved in the management and planning of urban systems.

The implementation of an analytical space syntax tool within a GIS provides some important advantages from both computational and user points of view. Incorporating 
space syntax in GIS promotes both GIS and urban morphology research. It enhances GIS functionality in spatial analysis into the domain of urban morphological analysis. On the other hand, GIS provides rich geo-referenced data, spatial data analysis and visualization capabilities for urban morphological research.

\subsection{Historic Cairo as Study Area}

The historic Cairo is located in the Cairo city Centre. The Centre of Cairo groups numerous streets and old dwellings and thus maintains, in the heart of the traditional urban fabric, forms of human settlement, which go back to the middle ages. The historic Centre of Cairo constitutes an impressive material witness to the international importance, on the political, strategic, intellectual and commercial level, of the city during the medieval period.

Conventional analysis of historical sites depends heavily on researches that focused on physical and social aspects of historical sites. The main emphasis of such approaches are to analyze the architectural style and characters, social life and activities within the urban fabric, and to different extents, to examine other issues related to the environmental and physical conditions of buildings. However, these analyzes exhibited an apparent lack in perceiving the "spatial configuration-social behavior" relationship. There have been various attempts to read the historical sites, particularly Fatimid Cairo. The research use a region of historic Cairo shown on Figure (1) as the case study to apply the space syntax approach on a GIS environment.

Figure (1) Darb Al-Ahmar Kessm Study area in historic Cairo

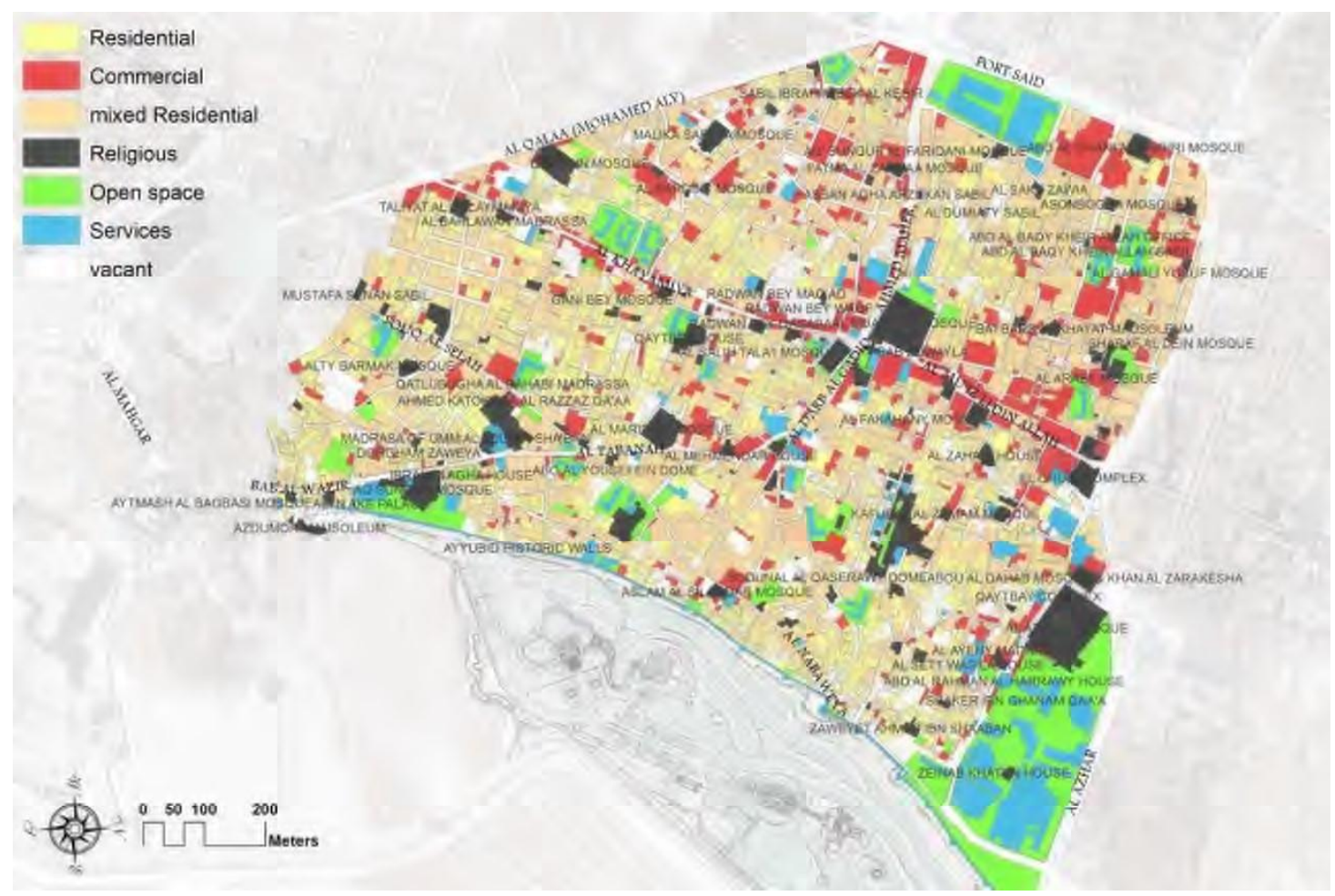




\section{SPACE SYNTAX SPATIAL MODELING}

The GIS spatial modeling of an urban environment for space syntax approach consists of two main objects: physical objects that are the spatial obstacles like buildings, and space objects that are defined as the parts of an urban space available for people movement, excluding by definition physical obstacles. This spatial data modeling constitutes the cognitive fundamental modeling reference of the space syntax approach, which differ from the ones generally used in GIS modeling, where free space is not represented as such by these models. The space objects are represented by two fundamental's concepts: the axial line, which is the one dimension space, which is relatively linear and the convex space concept, which is the two dimension non-linear space.

\subsection{Axial lines}

The axial lines are linear property represents the fact that the physical environment is relatively dense so the free space is stretched in one orientation at most points. When humans are walking along this type of free space is perceived as a "Vista" which can be approximately represented as an axial line. Axial lines are used in space syntax to simplify connections between spaces that make up an urban morphology. Usually they are defined by partitioning the space into the smallest number of largest convex subdivisions and defining these lines as those that link these spaces together. These can then form the basis for ranking the relative importance of the underlying spatial subdivisions and associating this with measures of urban intensity, density, or traffic flow. The axial line has been shown to produce a specific representation of the city that is closer to the cognitive representation that people use to navigate the city $[16,10]$. The axial model of the street network is a representation of the accessibility and visibility axis that the built environment allows through its structure. The axial representation is constructed through the drawing of lines that show the longest lines of accessibility and visibility within a given built environment.

Figure (2) shows the automatic construction of axial lines in historic Cairo region using a GIS/Space syntax package. The axial lines is an essential element for the sequential vision analysis and it reflects the possible visual experience of passersby and was captured by sequential photo images while approaching or moving on the visual corridors.

For the urban analysis purpose, the axial lines are classified with respect to its length using a natural break statistics classes. The short axis within a zone characterize the visual corridors with an interactive, interesting and surprising visual perception for the passers of the visual elements of corridors. On the other hand, long axial line corridors are characterized by the dull, uninteresting visual perception for corridor passers. The historic Cairo has overcome the dull effects of longest axis by the activities along he long visual corridors and can be solved by the intrusion of landscape elements within the corridors such as change level by stairs, hardscape and landscape elements. 
Figure (2) Axial lines map of historic Cairo study area

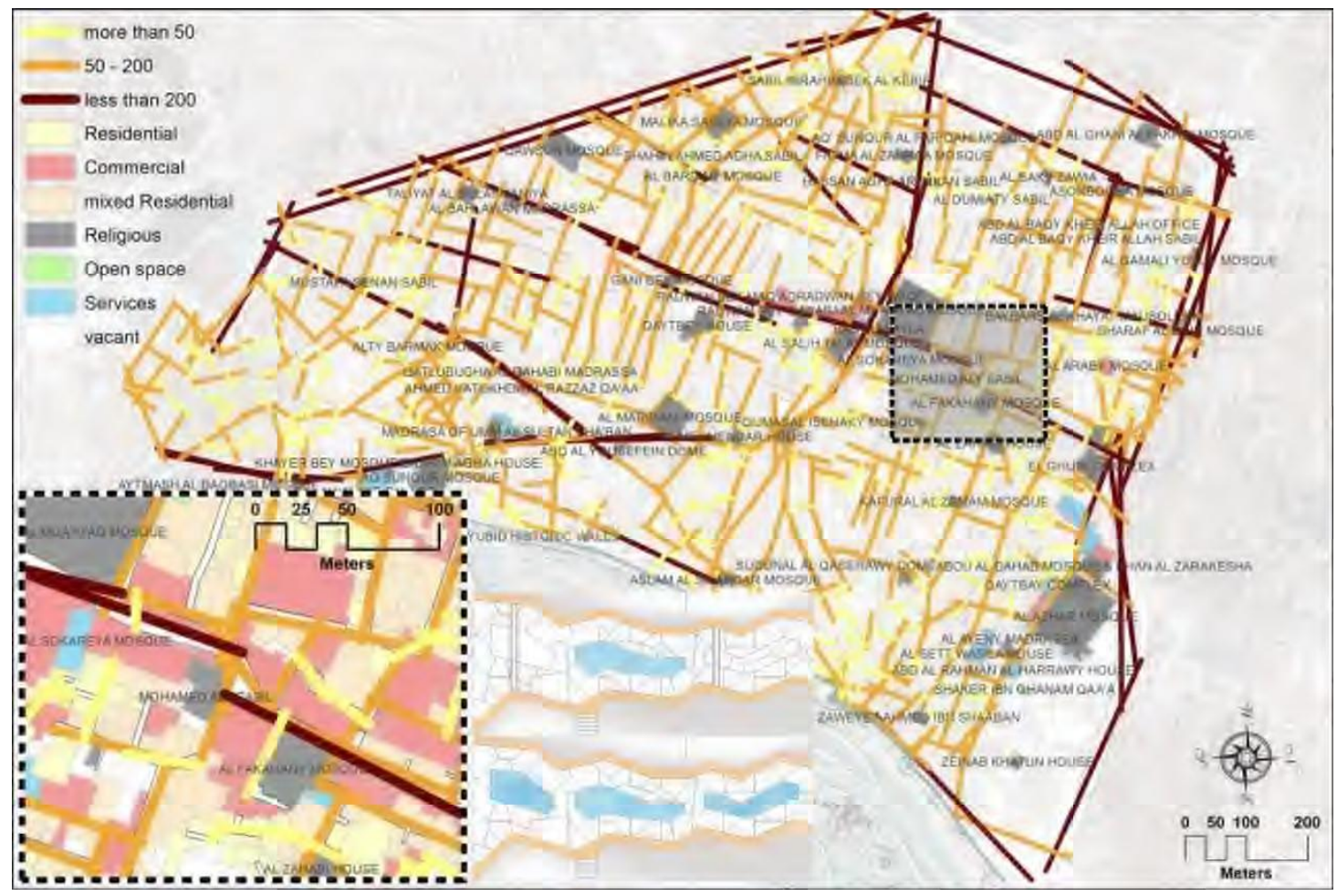

Table (1) shows that the Darb Al-Ahmar is characterized by short and medium visual axis which formed around $95 \%$ of axial lines. The relationship of the street network and the surrounding built environment and its characteristics such as land use and socio-economic indicators is an important factor that cannot be overlooked. Using this relation, axial lines can be used for location of landmarks and special land uses.

Table (1) Numbers of axial map and classification

\begin{tabular}{|c|c|c|}
\hline Axial Line Type & Count & $\begin{array}{l}\text { Cumulative } \\
\text { Frequency }\end{array}$ \\
\hline Short axis ( less than $50 \mathrm{~m}$ ) & 543 & 54.03 \\
\hline Medium axis ( $50 m-200 m)$ & 413 & 41.09 \\
\hline Long axis ( $200 \mathrm{~m}$ and higher) & 49 & 4.88 \\
\hline & 1005 & 100.00 \\
\hline
\end{tabular}

\subsection{Convex spaces}

A convex space is the convex polygon of a space where no line drawn between any two points in that polygon goes outside the polygon. Therefore, the second representation partitions the free space as a finite number of convex spaces that are represented by convex polygon in $2 \mathrm{D}$ maps. The second representation, so called convex representation, should comprise the least set of the fattest spaces that covers the completely free space.

Space syntax describes and analyzes the space form. The convex space analysis predict human behavior in space and how they perceive its form. People behavior showed that a person prefer to pause and linger on in the 'inside corners' of spaces [25]. GIS 
and space syntax attempts to define the convex spaces and guide the urban designer for the different spaces as pedestrians will perceive them as shown on Figure (3).

Figure (3) Convex space

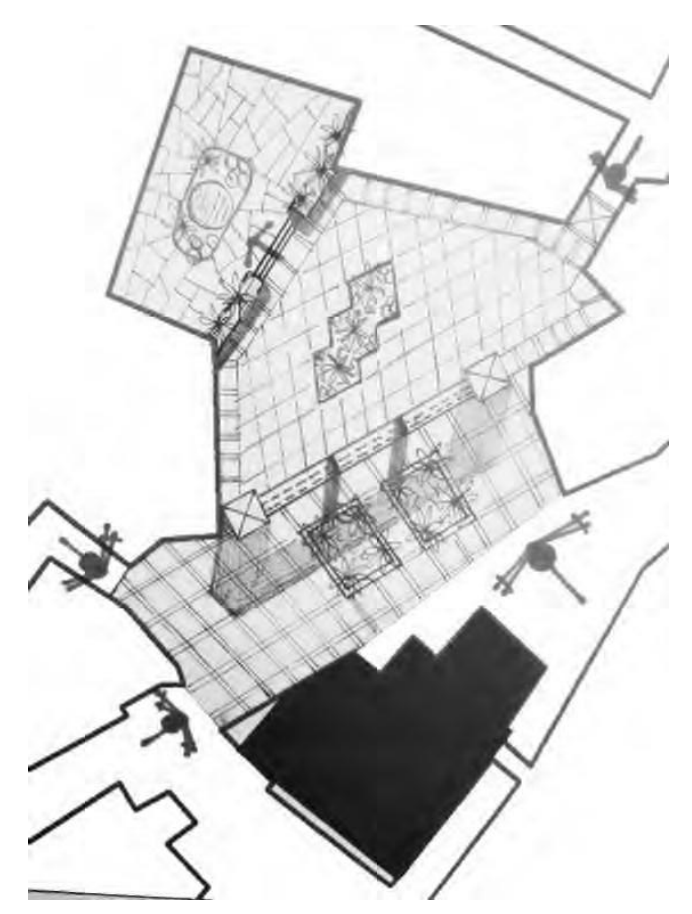

\section{SPACE SYNTAX SPATIAL ANALYSIS}

The theory of Space Syntax offers a method and spatial models of quantifying the various levels of topological relationships within a layout with respect to visual and pedestrian movement and behavior on city spaces. The Space Syntax theory offers different order levels of parameters and spatial analysis measures. The paper in next sections will discussed and applied those parameters and measure on the historic Cairo study area.

\subsection{Visibility Graphs Analysis VGA}

Visibility graphs analyze the extent to which any point in the spatial system is visible from any other. Where points are not directly visible, graph measures of a matrix of points can be calculated to test how many intervening points are needed for one point to see others. Published research, such as the Tate Gallery [20], findings on the extent to which the occupancy of a space by visitors could be explained by a combination of their area and mean depth within the visibility graph. The VGA analysis is used for visual analysis of building's façade and the corridor exposure studies and distribution of activities. Figure (4) shows the VGA analysis on Al Maridani mosque on Al Tabanah Street on Ghouriya shiyakha. The VGA support the decision of the urban designer to maximize the visual perception of such building.

The urban designer might use lighting and landscape elements distribution to ensure the visual attraction of the mosque. 
Figure (4) Visibility Graphical Analysis (VGA)

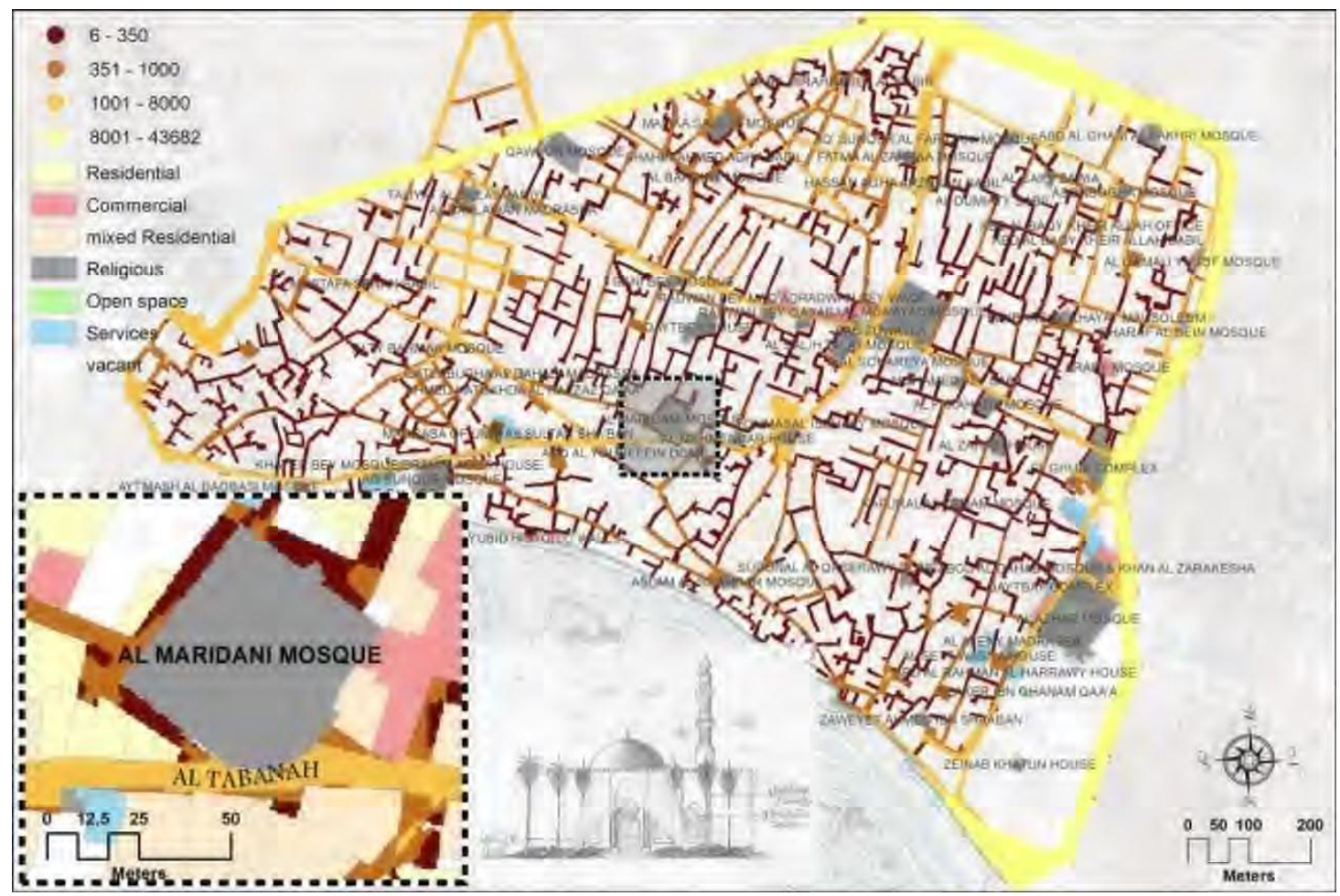

\subsection{Integration measure}

The concept of integration is depends on the idea of depth and not only the metric distance to define a space in relation to all other spaces in the system. The integration measure is the value of the function of the mean number of axial lines and connections that need to be taken from one space to all other spaces in the system. This integration value measures the relative position of any space or axial line with respect to the overall system. Thus, from a space with a high integration value, fewer changes in direction are necessary in order to move from that space to all other spaces in the system. The space segments that require the least amount of turns to reach all other streets are called 'most integrate. Integration can be analyzed in local scale with limited turns and is named local integration measure while the global integration measure used the whole space system for the analysis.

Integration measure is often argued to 'predict' the pedestrian use of a space. It is argued that the easier it is to reach a space, the more popularly it should be used. While there is some evidence of this being true, the method is also biased towards long, straight axial lines that intersect with lots of other spaces. Integration measure depends mainly on three spatial property parameters derived from space syntax theory and topological spatial analysis of GIS. These parameters is the fundamental of morphological analysis of integration.

\section{a. Connectivity Parameter}

The connectivity is the most apparent parameter for morphological analysis. Connectivity is an important Space Syntax parameter. This refers to the number of 
other axial lines or spaces that are directly connected to any one line or space. Since this information is directly observable from a space, it is considered a local measure.

$$
C_{i}=k
$$

\section{b. Control Parameter}

The second parameter is control value. The control value is by definition a parameter, which expresses the degree of choice each node represents for its directly linked nodes. The control value ( $c$ trli ) of a node $(i)$ is determined according to the following calculation:

$$
\operatorname{Ctrl}_{i}=\sum_{j=1}^{k} \frac{1}{C_{j}}
$$

Where $k$ is the number of directly linked nodes of a considered node $(i)$, and $C j$ is the Connectivity of the $j$ th directly linked node.

\section{c. Depth Parameter}

Another space syntax parameter is the depth. Depth is defined as the number of steps from a considered node to all other nodes. A node is said to be deep if it is many steps far from other nodes; in contrast, a node is said to be shallow if it is only a few steps far from other nodes. Depth is not an independent parameter of the space syntax. However, it is an important variable for calculating the integration of a node. Let dij is the length of the shortest path joining between the two points $i$ and $j$, then the total depth of node $i$ is the sum of distance and accordingly mean depth is defined by $M D$

$$
M D_{i}=\frac{\sum_{j=1}^{n} d_{i j}}{n-1}
$$

Where $n$ is the number of nodes of a whole study area.

These parameters can be used to describe both local and global properties of a spatial Configuration in the sense of integration or segregation. This concept is measured the depth parameter for global integration. Similarly, connectivity and local integration measure the degree of integration or segregation at the local level. The integration analysis, local integration and global integration, has applied on historic Cairo as shown on Figure (5). The integration of a node is by definition a value which indicates the degree to which a node is more integrated or segregated from a system as a whole (global integration), or from a partial system consisting of nodes within a few depth away (local integration). 
Figure (5) Local Integration Measure ( LIM)

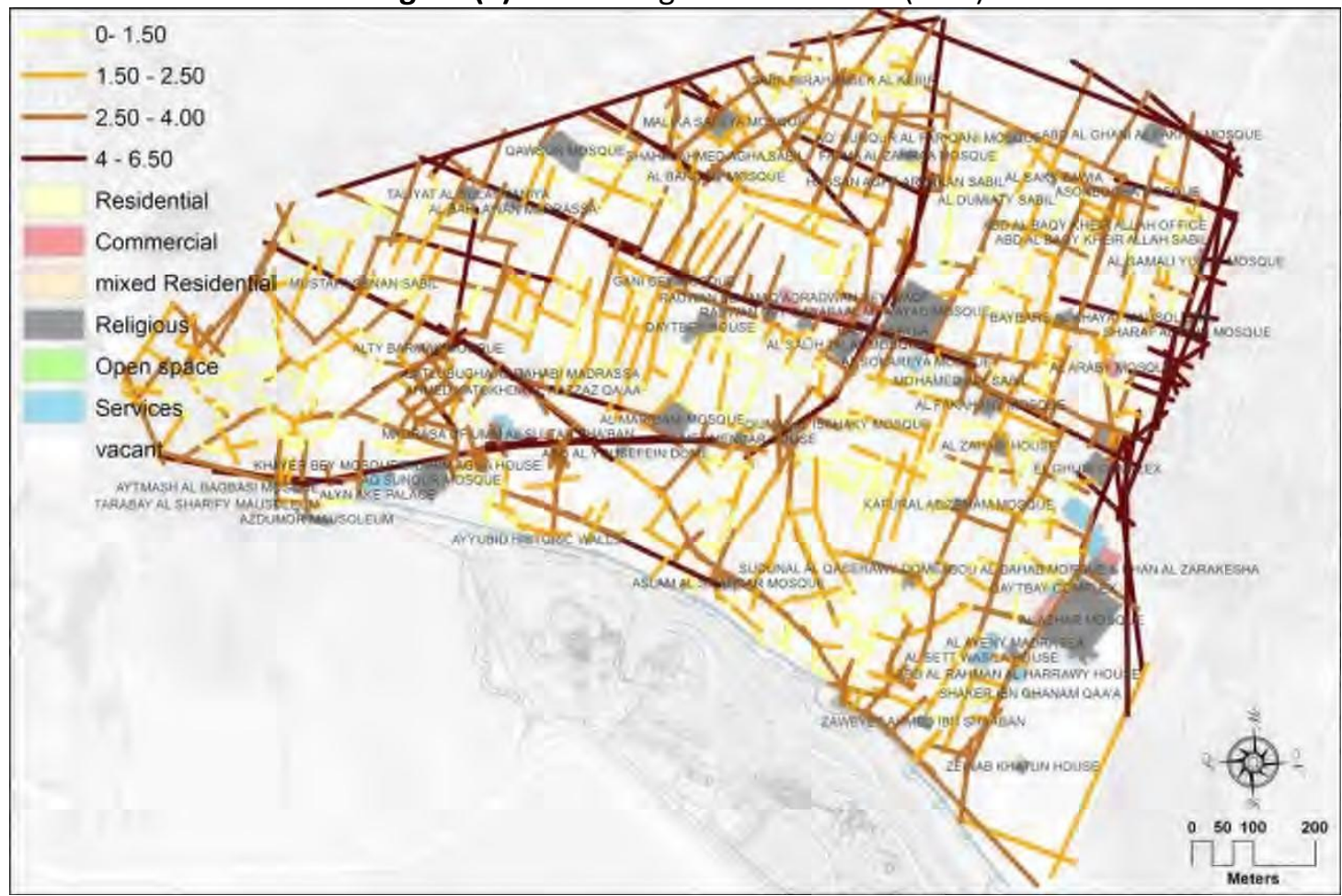

The local integration measure analyze how is each space is integrated within the local system of the space. The local integration measure shows the cognitive complexity of reaching a street by living pedestrians, and is often argued to 'predict' the pedestrian use of a street. It is argued that the easier it is to reach a street, the more popularly it should be used [20]. While there is some evidence of this being true, the method is also biased towards long, straight streets that intersect with lots of other streets [12]. As shown, we can conclude that the Shyakha Megharbelin is characterized with low local integrated corridors and there is disintegration between the corridors of this shykha.

Figure (6) shows the global integration measure GIM of the study area. The GIM shows that the corridors along AL-Moaz Street have their visual and mentally perceived by the visitors of the study area. The GIM index also is low for shyakha El Ghouriya,Haret El Room and Al-Batneya which lead for security risk on such shyakha.

\subsection{Intelligibility measure}

Basically there is a correlation between local and global parameters. Such correlation is termed as intelligibility, which is used to describe the part-whole relationship within the spatial configuration. It is defined by the co-efficiency of correlation between local and global parameters. A local area is said to be intelligible if its coefficiency value is higher than the one of global area. Intelligibility analysis using the correlation between connectivity and the global integration $(\mathrm{Rn})$ to give a clue of how the urban system is clear to its users. Applying the intelligibility for two zones on the study area to compare between the perception of both zones and how the visitors mentally and visually perceive them. 
Figure (6) Global Integration Measure (GIM)

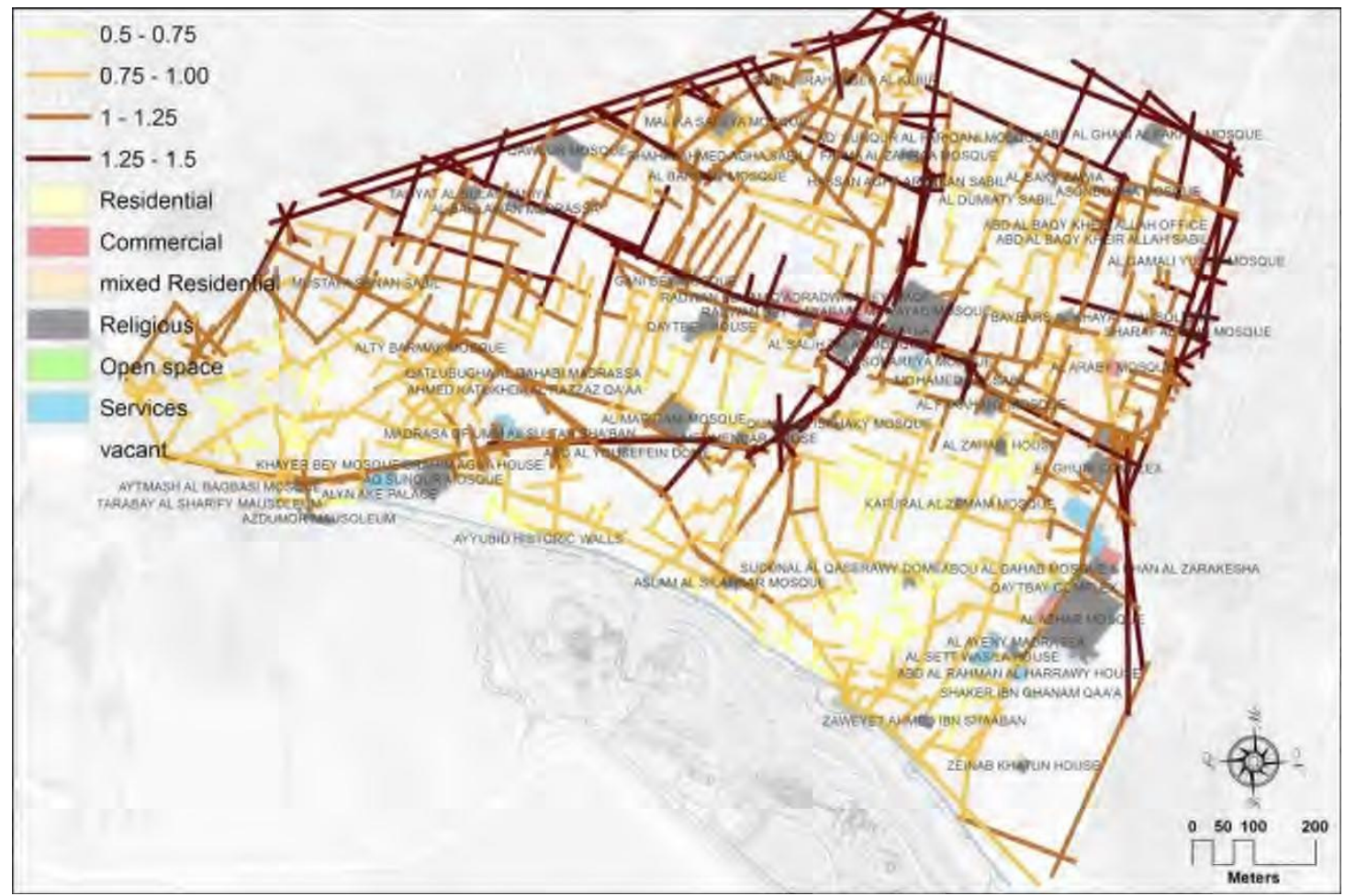

Figure (7) shows a comparative study for intelligibility of two zones on the study area Zone1: Darb Saada and Taht Al- Rabaa and Zone2: Quarbiya and Dawwoudiya.

The intelligibility of zone 1 is higher than zone 2 which means that the passers can find their way easier in zone 1 and they can perceive their location easier. In an intelligible zone, such as zone 1, the correlation between local and global properties of space is perfect, so the whole can be read from the part. Conversely, if the correlation is poor, zone 2 , the product will be unintelligible environment, so the people may lose their way [21]. (Figure 8)

Figure (7) Intelligibility comparative zones

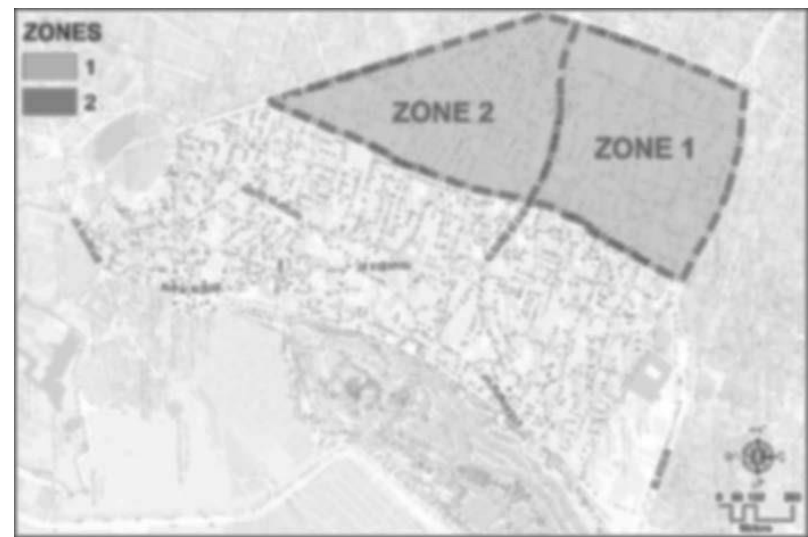


Figure (8) Scatter diagrams for intelligibility measure

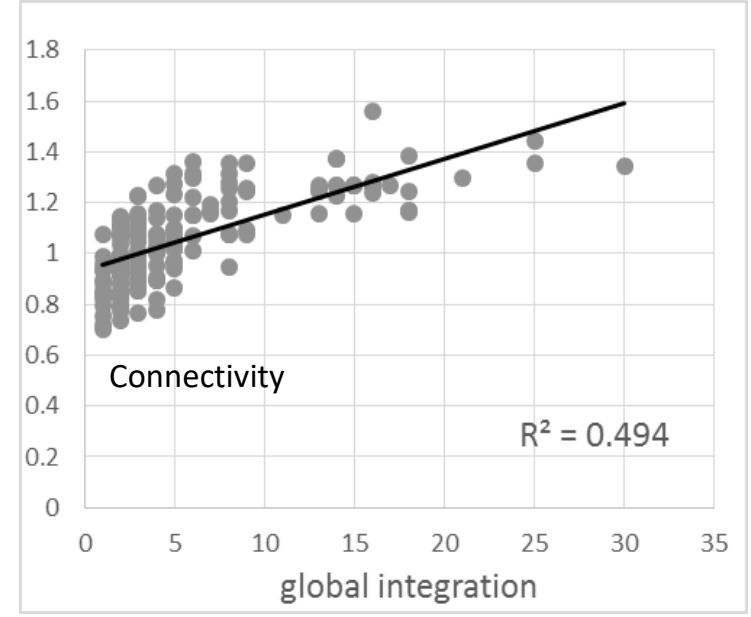

Zone 1

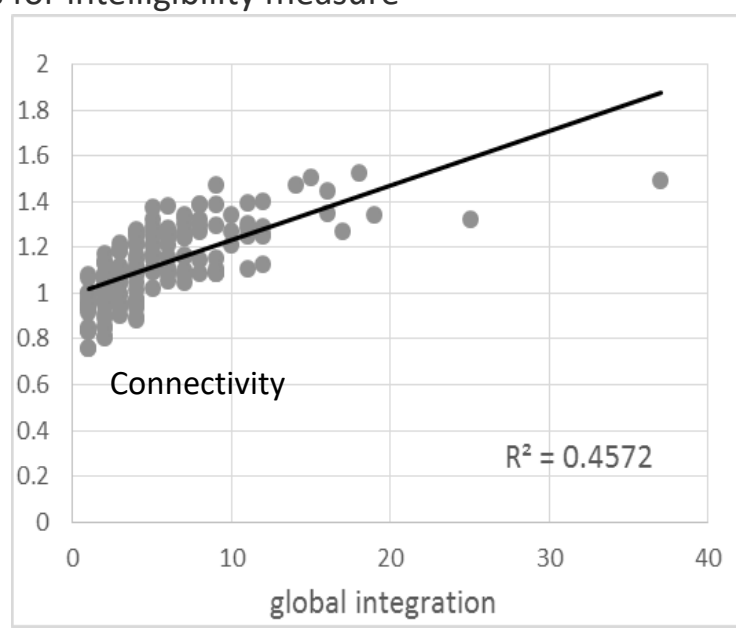

Zone 2

\subsection{Synergy measure}

Synergy measure is a correlation between global integration and local integration. It is used to indicate the relationship between local parts and global parts [23]. Synergy indicates the relationship between the local economy of a zone and the whole study area economy. The synergy answer the question do the corridors which connect the whole spaces through the zone as those which form the heart of the study area?. From the scatter diagram of figure (9) we can conclude that zone 1 and Zone 2 have same visual pattern characteristics and almost the same as the study area as whole.

Figure (9) Scatter diagrams for synergy measure

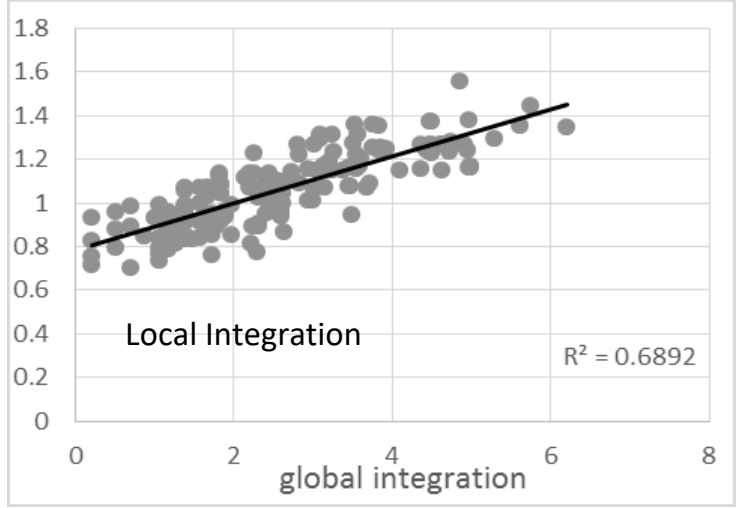

Zone 1

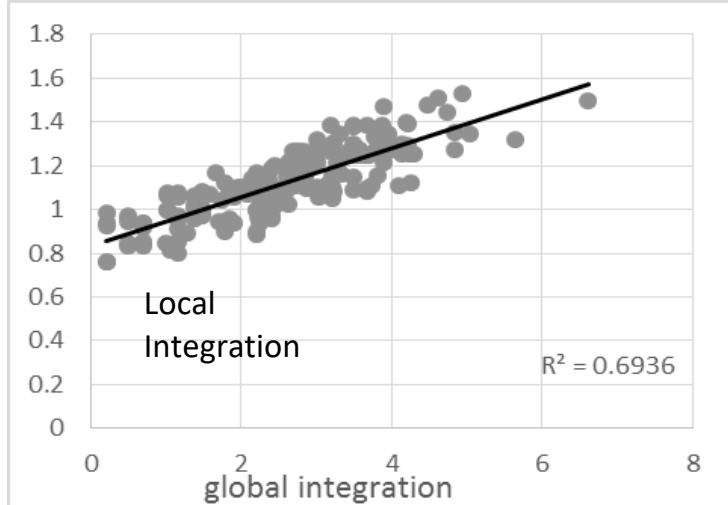

Zone 2

\section{Movement Core Analysis (MCA)}

The Space Syntax methodology investigates relationships between spatial layout and a range of social, economic and environmental phenomena. These phenomena include patterns of movement, awareness and interaction; land use density, land use mix and land value, safety and crime distribution [16]. 
A study of local movement core LMC and global movement core GMC that identify the relation between urban morphology parameters for pedestrian movements and land use analysis. The movement core attempts to correlate the control parameter representing the spatial parameter for the urban morphology and the integration measure as a pedestrian behavior indicator.

Figure (10) shows the multiple variables where integration and control parameter will take $\mathrm{H}$ : high value and $\mathrm{L}$ : low value consequently.

The Global movement core relates the global integration with the control parameter to evaluate the relocation for activities and residential land use. The corridors with $\mathrm{H}$ $H$ values are corridors for visitors land use such as Al Moaz street.

In the other hand, the local movement core studied the local pedestrian behavior. The analysis will lead to evaluation of the locations of local services and commercial land uses as schools, public buildings for inhabitants on corridors with $\mathrm{H}-\mathrm{H}$ values, while residential areas must be located on L-L and L-H values - Figure (11).

\section{CONCLUSIONS}

A successful development of GIS still implies the integration of new analysis and modeling methods for environmental and urban planning. Over the past years, space syntax has provided an important experimental contribution to the analysis of urban morphology. However, the diffusion of space syntax principles requires the diffusion of its modeling principles and capabilities within the GIS community, which is nowadays largely involved in urban studies.

The research described in this paper introduces the principles and modeling concepts of space syntax and some of its main spatial measure and parameters that support computational modeling and analysis of a spatial configuration for urban planning and design. The implementation of space syntax parameters and measure are within a GIS platform, namely, the Axwoman and Depthmapx UCL prototype.

The research illustrates different quantified, analytical functions for urban morphological analysis in the context of historic Cairo case studies.

The space syntax approach within GIS environment provides an efficient experimental approach to the understanding of spatial configuration and a new quantification tools for urban design. 
Figure (10) Global Movement Core (GMC)

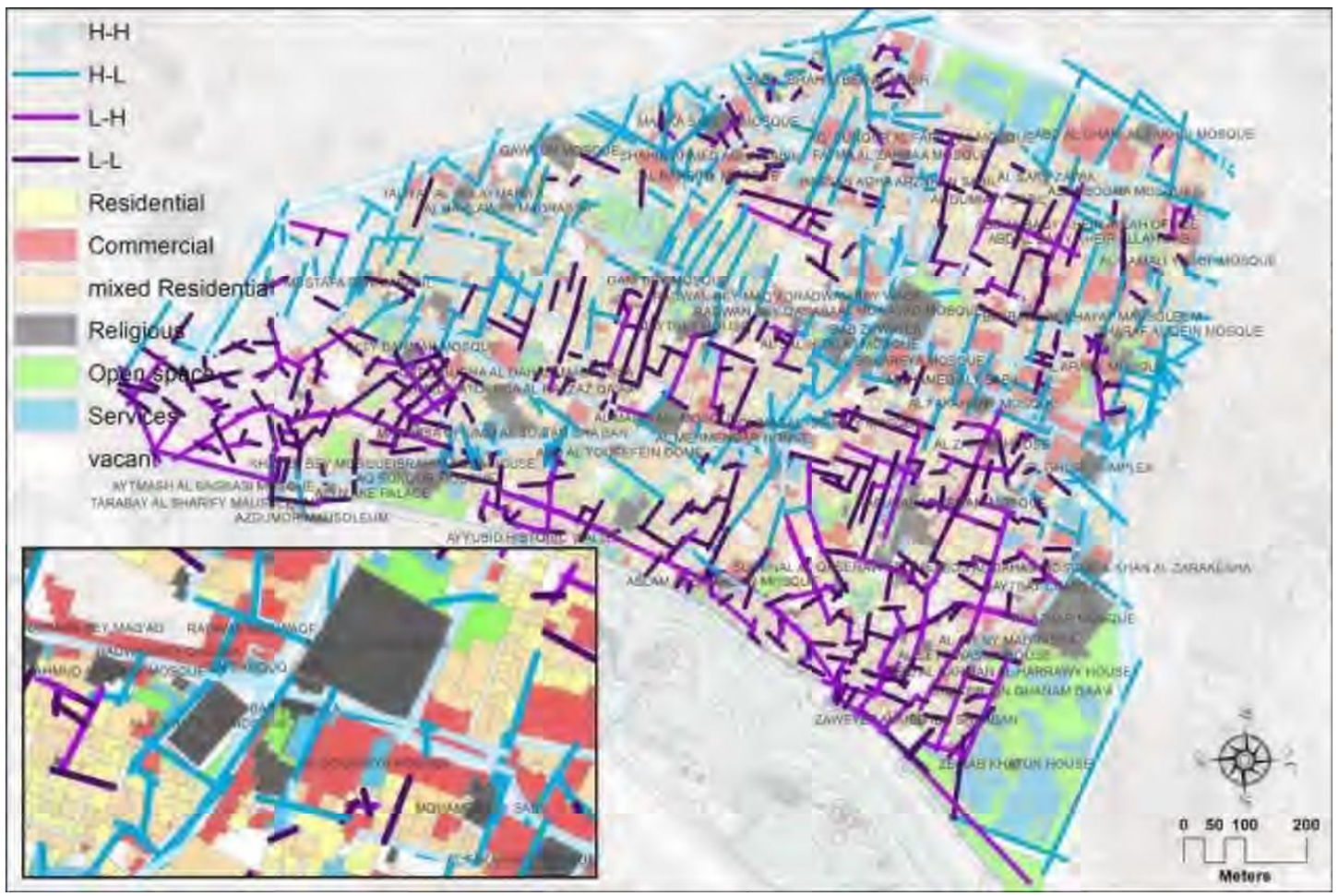

Figure (11) Local Movement Core (LMC)

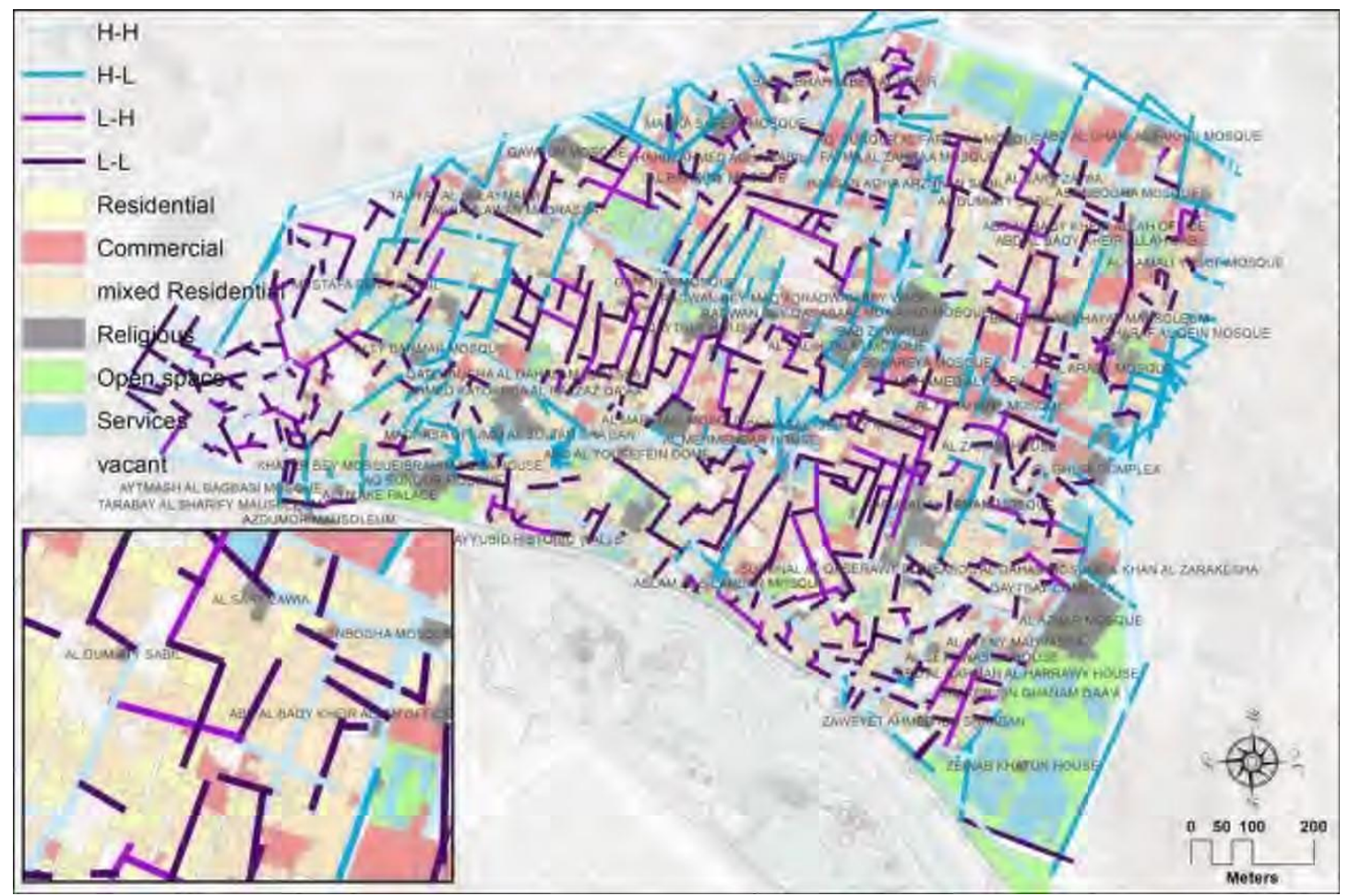




\section{REFERENCES}

1. Batty, M., R. Conroy, et al. 1998. The Virtual Tate. London, CASA.

2. Conroy Dalton, R., Bafna, S., 2003. The syntactical image of the city: A reciprocal definition of spatial elements and spatial syntaxes, in: Hanson, J. (Ed.), 4th International Space Syntax Symposium. UCL, London, pp. 59.51-59.23.

3. Dhanani, A., L. Vaughan, C. Ellul, and S. Griffiths. 2012. From the Axial Line to the Walked line: Evaluating the Utility of Commercial and User-Generated Street Network Datasets in Space Syntax Analysis, $8^{\text {th }}$ International Symposium

4. Flanagin, A.J., Metzger, M.J., 2008. The credibility of volunteered geographic information. GeoJournal 72 (3), 137-148. Proceedings: Eighth International Space Syntax Symposium. Santiago de Chile: PUC, 2012. 8211:32

5. Fotheringham S. and Wegener M. 2000. Spatial Models and GIS: New Potential and New Models, Taylor and Francis, London.

6. Haklay, M., 2010. How good is volunteered geographical information? A comparative study of Open Street Map and Ordnance Survey datasets. Environment and planning B: Planning and design 37 (4), 682-703.

7. Haklay, M., Weber, P., 2008. Open Street Map: User-generated street maps. Pervasive Computing, IEEE 7 (4), 12-18.

8. Hillier, B., 2003. The architectures of seeing and going: or, are cities shaped by bodies or minds? And is there a syntax of spatial cognition?, in: Hanson, J. (Ed.), Fourth International Space Syntax Symposium. University College London, London.

9. Hillier, B., Penn, A., 2004. Rejoinder to Carlo Ratti. Environment and planning B: Planning and design 31, 501-511.

10. Hillier, B. 1998. Space is the Machine. Cambridge University Press.

11. Hooper, A; Punter, J. (2006) Capital Cardiff 1975-2020, Regeneration, Competitiveness and the Urban Environment. University of Wales Press

12. Jung, C. and M. Choi. 2010. "Analysis of traffic volume using space syntax model supplemented byaccessibility factor in downtown Daegu." Journal of Korean Planning Association 45(5): 1129-140.

13. Morello, E., Ratti, C. 2009. A digital image of the city: 3D isovists in Lynch's urban analysis. Environment and Planning B: Planning and Design. 36, 837- 853.

14. Chih-Feng, S.S., 2000. Housing layout and crime vulnerability. URBAN DESIGN International 5, 177-188.

15. Miller, H., 2000. Geographic representation in spatial analysis. Journal of Geographical Systems 2 (1), 55-60.

16. Miller, H., Wentz, A,. 2003. Representation and spatial analysis in geographic information systems. Annals of the Association of American Geographers 93 (3), 574594. OSM., 2011. www.openstreetmap.org website, access date 12/07/2011.

17. Penn, A., 2003. Space Syntax And Spatial Cognition: Or Why the Axial Line? Environment and Behavior 35 (1), 30-65. 
18. Ratti, C., 2004. Rejoinder to Hillier and Penn. Environment and planning B: Planning and design 31, 513-516.

19. Rao, X.J., and H.F. Wang. 2012. A Morphological History of Urban Centers in Qingdao. $8^{\text {th }}$ International Symposium

20. Ratti, C., 2004b. Space syntax: some inconsistencies. Environment and planning B: Planning and design 31(4), 487-499.

21. Suleiman, W., Joliveau, T., Favier, E. 2011. 3D Urban Visibility Analysis with Vector GISData.. University of Portsmouth, UK , 27-29 avril 2011.

22. Turner, A. and A. Penn. 1999. Making Isovists Syntactic: Isovist Integration Analysis. Proceedings of the Second Space Syntax Symposium, Brasilia, Brasil.

23. Turner, A., 2001. Depthmap: A Program to Perform Visibility Graph Analysis, in: Peponis, J., Wineman, J.,Bafna, S. (Eds.), Third International Space Syntax Symposium, Atlanta, Georgia.

24. Turner, A., 2007. From axial to road-centre lines: a new representation for space syntax and a new model of route choice for transport network analysis. Environment and Planning B 34 (3), 539-555.

25. Turner, A., 2009. Stitching Together the Fabric of Space and Society: An Investigation into the Linkage of the Local to Regional Continuum, in: Daniel Koch, Lars Marcus, Jesper Steen (Eds.), Seventh International Space Syntax Symposium. Royal Institute of Technology, Stockholm, Stockholm, pp. 116:111-116:112.

26. Vaughan, L., 2011. The nature of suburbia - change and continuity, in: Centre for London (Ed.), The big (suburban) society - community, identity and amenity in outer London. Demos and London School of Economics and Political Science, London.

27. Whitehand, J. W. R. and Morton, N. J. (2006) The Fringe-belt Phenomenon and Socioeconomic Change. Urban Studies, Vol. 43, No. 11, 2047-2066, October 2006

28. Wilson, A. (2000) Complex Spatial Systems. The Modeling Foundations of Urban and Regional Analysis. Prentice Hall. 